“C 2019 IEEE. Personal use of this material is permitted. Permission from IEEE must be obtained for all other uses, in any current or future media, including reprinting/republishing this material for advertising or promotional purposes, creating new collective works, for resale or redistribution to servers or lists, or reuse of any copyrighted component of this work in other works." 


\section{An aggregator-based-strategy to minimize the cost of energy consumption by optimal utilization of energy resources in an apartment building}

\author{
Sohaib Rafique \\ School of Engineering \\ Macquarie University \\ Sydney, Australia \\ sohaib.rafique@gmail.com \\ Jahangir Hossain \\ School of Engineering \\ Macquarie University \\ Sydney, Australia \\ jahangir.hossain@mq.edu.au
}

\author{
Mohammad Sohrab Hasan Nizami \\ School of Engineering \\ Macquarie University \\ Sydney, Australia \\ sohrab.nizami@hdr.mq.edu.au
}

\author{
Graham Town \\ School of Engineering \\ Macquarie University \\ Sydney, Australia \\ graham.town@mq.edu.au
}

\author{
Usama Bin Irshad \\ School of Engineering \\ Macquarie University \\ Sydney, Australia \\ usama.irshad@hdr.mq.edu.au
}

\begin{abstract}
Buildings and transport consume two thirds of the total global energy. It is desirable to maximize the use of renewable generation in these sectors, and to optimize the use of that energy by managing diverse sources and loads. This is particularly challenging in high-density residential premises where the space for such infrastructure is limited, and storage can have significant impact on energy utilization and demand. In this paper, we have proposed an aggregator-based-strategy (ABS) to optimally utilize the available energy resources and storage in an apartment building with twenty households, each having an electric vehicle (EV), and an aggregated solar photovoltaic (PV) energy and stationary battery storage (BS) system. The strategy is flexible and can be applied to any building with EVs, solar PV and BS to minimize the cost of energy consumption without compromising the flexibility of energy usage or travel requirements. The model also accounts for the battery capacity degradation and its associated cost to make it more realistic. The model is evaluated using real data and the results show that the strategy not only reduces the cost of energy consumption but also reduces the amount of energy drawn from the grid significantly.
\end{abstract}

Keywords-optimization, electric vehicles, solar pv, battery storage, apartment building, aggregator, cost reduction, battery degradation

\section{NOMENCLATURE}

$n_{t} \in\{0,1\}=$ energy purchase at ' $\mathrm{t}$ '

$m_{t} \in\{0,1\}=$ energy sell at ' $\mathrm{t}$ '

$o_{t} \in\{0,1\}=$ Battery Storage (BS) charging at ' $\mathrm{t}$ '

$s_{t} \in\{0,1\}=$ BS discharging at ' $\mathrm{t}$ '

$u_{t, h} \in\{0,1\}=$ Electric Vehicle (EV) charging for ' $h$ ' at ' $\mathrm{t}$ '

$v_{t, h} \in\{0,1\}=$ EV discharge for ' $h$ ' at ' $\mathrm{t}$ '

$\lambda_{t}^{+}=$cost of energy purchase at ' $\mathrm{t}$ ' (cents/kWh)

$\lambda_{t}^{-}=$cost of energy sell at ' $\mathrm{t}$ ' (cents $\left./ \mathrm{kWh}\right)$

$\theta^{\text {deg }}=$ battery degradation cost per charge/discharge $(\$ / \mathrm{Wh})$

$C_{t}^{B(\text { deg })}=$ BS capacity degradation cost at ' $\mathrm{t}$ ' due to charging/discharging

$C_{t}^{E V(d e g)}=$ cumulative cost of EV battery capacity degradation at ' $\mathrm{t}$ ' due to charging/discharging

$\rho_{(c / d)}^{B}=$ charging/discharging power of BS $(\mathrm{kW})$

$\rho_{(c / d)}^{E V}=$ charging/discharging power of EV battery $(\mathrm{kW})$

$V^{B}=$ terminal voltage of $\mathrm{BS}$ (volts)

$V^{E V}=$ terminal voltage of $\mathrm{EV}$ battery in (volts)

$\vartheta\left(\rho_{c / d}\right)=$ battery capacity degradation per charge/discharge

$E_{t}=$ net system energy at ' $\mathrm{t}$ ' $(\mathrm{kWh})$

$E_{t}^{g}=$ energy from/to grid at ' $\mathrm{t}$ ' $(\mathrm{kWh})$

$E_{t}^{P V}=$ energy generated by solar photo-voltaic $(\mathrm{PV})$ at ' $\mathrm{t}$ ' $(\mathrm{kWh})$

$E_{t}^{e x}=$ energy exchange with household/EV at ' $\mathrm{t}$ ' $(\mathrm{kWh})$

S.R., U.I, and M.S.H. are supported by Macquarie University Research Scholarships.
$E_{t, h}^{H}=$ energy consumption of ' $\mathrm{h}$ ' at ' $\mathrm{t}$ ' (kWh)

$E_{t, h}^{d t}=$ energy consumed due to distance travel by EV of ' $\mathrm{h}$ ' at ' $\mathrm{t}$ ' (kWh)

$\delta_{t}^{B}=$ State-of-Charge (SoC) of BS at ' $t$ ' (\%)

$\delta_{t, h}^{E V}=$ SoC of EV battery of 'h' at 't' (\%)

$\delta_{t, h}^{D T}=$ SoC required by EV of 'h' at ' $t$ ' for travel needs (\%)

$\delta_{t, h}^{\text {des }}=$ desired SoC of EV of 'h' at 't' (\%)

$E_{\max }^{B}=\max$ energy capacity of BS $(\mathrm{kWh})$

$E_{\max }^{E V}=$ max energy capacity of $\mathrm{EV}$ of ' $\mathrm{h}$ ' $(\mathrm{kWh})$

$E_{t}^{B(C)}=$ energy required to charge BS at ' $\mathrm{t}$ ' $(\mathrm{kWh})$

$E_{t}^{B(D)}=$ energy discharged by BS at ' $\mathrm{t}$ ' ( $\left.\mathrm{kWh}\right)$

$E_{t, h}^{E V(C)}=$ energy required to charge EV battery of ' $\mathrm{h}$ ' at ' $\mathrm{t}$ '

$E_{t, h}^{E V(D)}=$ energy discharged by EV battery of ' $\mathrm{h}$ ' at ' $\mathrm{t}$ '

$\alpha_{t, h} \in\{0,1\}=\mathrm{EV}$ availability matrix for 'h' at ' $\mathrm{t}$ '

Other variables, parameters, notations and abbreviations are described in the paper below.

\section{INTRODUCTION}

Thermal management of buildings accounts for approximately $40 \%$ of global energy consumption and the transport sector is responsible for about $28 \%$ of energy consumption globally, the majority of which is provided from carbon-based energy resources [1]. To minimize the cost of energy whilst also minimizing carbon-based energy usage requires an increase in the proportion of renewable energy generation and careful management of the diverse sources, loads, and storage in the two sectors. This is particularly challenging in high-density residential premises where the space for renewable energy generation infrastructure is very limited. With the advent of smart grid technology, Building Energy Management Systems can be designed to optimize the use of available energy resources against predefined criteria, e.g. to minimize cost, energy consumption, peak load, etc.

Electrification of the transport is expected over coming decades [2]. The relatively large batteries in electric vehicles (EVs) can be used to support the electricity grid, e.g. by provision of vehicle-to-grid (V2G) services [3]. For an apartment building with a limited number of solar photovoltaic (PV) panels, battery storage (BS) and the EVs, there should be an energy management system (EMS) to ensure optimal utilization of the available energy resources without compromising the needs of energy consumers (households and EV owners).

This paper is motivated by the challenges associated with the intermittent nature of the renewable energy resources and the opportunities presented by the uncertainties associated 
with EV usage. In this paper, we have proposed an aggregatorbased-strategy (ABS) to minimize the cost of energy consumption for an aggregator, by optimal utilization of the available energy resources in an apartment building. The paper is organized as follows; Section II put this work in the context of other publications. Section III describes the methodology used in our work, Section IV presents our analysis and results. Section V discusses the practical applications of the proposed strategy. Section VI contains the summary and conclusion.

\section{LITERATURE REVIEW}

In this section we summarize research relevant to optimal utilization of solar PV, battery storage and EVs for buildings. Methods to minimize the cost of electricity in low density residential buildings containing some renewable energy generation and stationary storage were presented in [4]-[6]. The latter works did not consider the strong constraints on renewable generation capacity applicable in apartment buildings, nor did they consider charging and discharging of EVs.

In [7], authors examined the charging strategies of multiple (PHEVs) in an apartment building, equipped with a solar PV generation. In [8], the authors proposed a model to schedule the charge/discharge of EVs to reduce customer cost. In [9], [10], the authors proposed an EMS for apartment building with Vehicle-to-Home (V2H) systems. In [11], a Home Energy Management System (HEMS) was presented using the battery of an EV/PHV. The latter works did not include fixed battery storage.

In [12], the authors proposed flexible vehicle-to-grid (V2G) coordination schemes for office buildings equipped with electric vehicle (EV) charging stations. In [13], the authors analyzed the impact of solar PV systems on battery storage and EVs in micro-grids. These works were based on non-residential buildings where energy consumption constraints and arrival/departures of vehicles are different compared to residential apartment building.

To the best of authors knowledge, to date no research has considered optimizing all possible energy resources in a single model while also considering battery capacity degradation and its associated cost; these are the key contributions of this paper.

\section{Methodology}

This section describes the developed model and the datasets used for analysis. The optimization problem considers the household energy consumption, power generation from solar PV panels, charging/discharging of EV batteries for $\mathrm{G} 2 \mathrm{~V}-\mathrm{V} 2 \mathrm{G}$ operations, discharging of $\mathrm{EV}$ batteries for travel needs and charging/discharging of battery storage. The model also considers battery capacity degradation and its associated cost as a function of charging/discharging power for each charge/discharge cycle.

We have formulated the mathematical model of the existing system and simulated the model using real data. We compared the proposed model with the base case (BC) model. The objective function and constraint equations were developed and simulated on MATLAB and GAMS. Due to the non-linear nature of the objective function, we used a commercially available MINLP (mixed integer non-linear programming) solver (i.e. GAMS [14]) and analyzed the results in MATLAB.

\section{A. Model details}

1) Base Case: The base case model follows the "Greedy" algorithm. The algorithm works as follows;

1. EVs are charged as soon as they arrive home, without considering the energy tariff rates

2. Discharging of EVs is not considered

3. Solar PV energy is utilized to charge the BS

4. BS discharges during the peak hours

GREEDY AlgorithM FOR BASE CASE MODEL

\begin{tabular}{cc}
\hline \hline & Base Case Pseudo Code \\
\hline If & 'Solar PV' is 'Available' \\
If & Tariff is 'Peak' \\
Then & Supply energy to the 'Load' \\
If & Tariff is 'Off-peak' \\
Then & Charge the 'BS' first \\
Then & Supply energy to the 'Load' \\
If & Solar PV' is 'Not-available' \\
Then & Supply the 'Load' first \\
Then & Charge the 'BS' \\
\hline \hline
\end{tabular}

2) Aggregator-based-strategy (ABS): The ABS is designed to minimize the cost of energy consumption for an 'aggregator', by optimal utilization of the available energy resources. It is assumed that the aggregator owns the solar PV and BS modules. Fig. 1 represents the energy exchange process flow for the ABS. The aggregator possesses an energy management system which is responsible for optimizing the utilization of available energy resources while considering associated constraints.

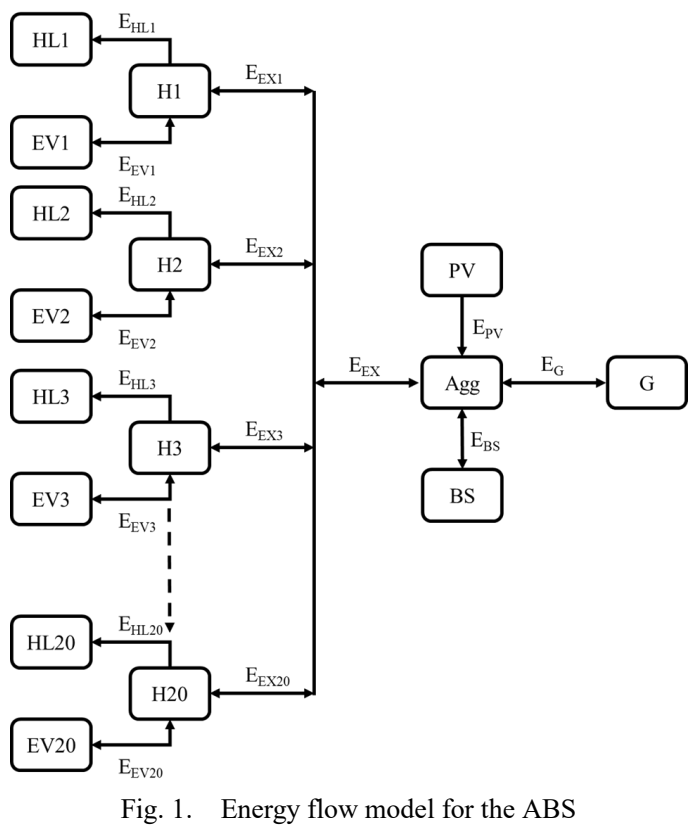

3) Assumptions:

1. EV is plugged-in, whenever it arrives home

2. Average energy consumption by an EV for distance travel is $0.16 \mathrm{kWh} / \mathrm{km}[15]$.

3. SoC $\left(\delta_{t, h}^{E V}\right)$ for all EVs at the beginning of the day is $50 \%$ which is realistic as majority of the cars stay at home during night time and have enough time to recharge [15].

4. Each EV should have the desired SoC before departure (19). 


\section{B. Mathematical Modelling}

The objective function (1) is the summation of electricity costs which is calculated by multiplying the net energy of the system ' $E_{t}$ ', the decision variables ' $n_{t}$ ' $\&$ ' $m_{t}$ ', and the cost of energy purchase ' $\lambda_{t}^{+}$' and cost of energy sold ' $\lambda_{t}^{-}$', respectively.

$$
\begin{aligned}
\text { Cost }=\sum_{t=1}^{T}\left(n_{t} E_{t} \lambda_{t}^{+}+m_{t} E_{t} \lambda_{t}^{-}\right. \\
\left.+C_{t}^{B(\text { deg })}+C_{t}^{E V(\text { deg })}\right)
\end{aligned}
$$

When ' $E_{t}$ ' is positive, ' $n=1 \& m=0$ ' the system 'purchase' energy from the grid. In other case, when the system has excess energy i.e. ' $E_{t}$ ' is negative, the system 'sell' energy to the grid. In each scenario there is a different timeof-use (TOU) tariff applied for sell/purchase of energy.

$$
\begin{gathered}
E_{t}=E_{t}^{g}-E_{t}^{e x} \\
E_{t}^{e x}=\sum_{h=1}^{H}\left(E_{t, h}^{H}+E_{t, h}^{E V(C)} \cdot u_{t, h} \cdot \alpha_{t, h}\right. \\
\left.-E_{t, h}^{E V(D)} \cdot v_{t, h} \cdot \alpha_{t, h}\right) \\
E_{t}^{g}+s_{t} \cdot E_{t}^{B(D)}+E_{t}^{P V} \\
=o_{t} \cdot E_{t}^{B(C)}+E_{t}^{e x}
\end{gathered}
$$

Here, ' $E_{t}^{g}$ ' is the energy exchange between the aggregator and the grid. ' $E_{t}^{e x}$ ' is the energy exchange between the aggregator and the houses. $+E_{t}^{g}$ is the energy purchased by the aggregator from grid and $-E_{t}^{g}$ is the energy sold by the aggregator to the grid. $+E_{t}^{e x}$ is the energy sold by the aggregator to the houses and $-E_{t}^{e x}$ is the energy purchased by the aggregator from the houses. Therefore, if the net energy ' $E_{t}$ ' is positive that means the aggregator has purchased energy at ' $\lambda_{t}^{+}$' and for this case ' $n=1 \& m=0$ '. In other case, when the net energy ' $E_{t}$ ' is negative, that means the aggregator has sold the energy to the grid at ' $\lambda_{t}^{-}$' (cost of selling energy) and for this case ' $n=0 \& m=1$ '.

$$
\begin{gathered}
n_{(t)}+m_{(t)}=1 \\
n_{(t)} \cdot m_{(t)}=0 \\
n_{(t)} \cdot E_{(t)} \geq 0 \\
m_{(t)} \cdot E_{(t)} \leq 0
\end{gathered}
$$

Equations $(5,6,7,8)$ represent the buying/selling of energy constraints for the model.

$$
\begin{gathered}
s_{(t)}+o_{(t)} \leq 1 \\
s_{(t)}+o_{(t)} \geq 0 \\
u_{(t, h)}+v_{(t, h)} \leq 1 \\
u_{(t, h)}+v_{(t, h)} \geq 0
\end{gathered}
$$

Equations $(9,10)$ represent the decision variables for charging/discharging of stationary battery and $(11,12)$ represent the decision variables for charging/discharging of EV batteries.

$$
\begin{aligned}
\delta_{(t)}^{B} & \geq \delta_{\min }^{B} \\
\delta_{(t)}^{B} & \leq \delta_{\max }^{B} \\
\delta_{(t, h)}^{E V} & \geq \delta_{\min }^{E V} \\
\delta_{(t, h)}^{E V} & \leq \delta_{\max }^{E V}
\end{aligned}
$$

Equations $(13,14,15,16)$ represent the upper and lower bounds of SoC for stationary battery and EV batteries respectively.

$$
\delta_{t}^{B}=\delta_{(t-1)}^{B}+\frac{o_{t} E_{t}^{B(C)}}{E_{\max }^{B}}-\frac{s_{t} E_{t}^{B(D)}}{E_{\max }^{B}}
$$

Equation (17) represents the SoC of stationary battery.

$$
\begin{array}{r}
\delta_{(t, h)}^{E V}=\delta_{(t-1, h)}^{E V}+\frac{E_{t, h}^{E V(C)} \cdot u_{t, h} \cdot \alpha_{t, h}}{E_{\text {max }}^{E V}} \\
-\frac{E_{t, h}^{E V(D)} \cdot v_{t, h} \cdot \alpha_{t, h}}{E_{\max }^{E V}} \\
\delta_{(t, h)}^{E V}=\delta_{(t-1, h)}^{E V}-\frac{\alpha_{t, h} \cdot E_{t, h}^{d t}}{E_{\max }^{E V}} \\
\delta_{(t, h)}^{E V} \geq \frac{\alpha_{t, h} \cdot E_{t, h}^{d t}}{E_{\max }^{E V}}
\end{array}
$$

Equations $(18,19,20)$ represent the SoC of EV batteries for respective households.

$$
\begin{aligned}
\vartheta\left(\rho_{(c / d)}\right)=\left(\beta_{1} V\right. & +\beta_{3} V^{2}+\beta_{5} V^{3} \\
& \left.+\beta_{7} V^{4}\right) \\
& +\left(\beta_{2}+\beta_{6} V\right) \cdot\left|\rho_{(c / d)}\right| \\
& +\frac{\beta_{4}}{V} \cdot\left|\rho_{(c / d)}\right|^{2}
\end{aligned}
$$

Equation (21) is the representation of battery degradation as function of charging/discharging power, inspired by [24].

$$
\begin{aligned}
& C_{t}^{B(\operatorname{deg})}=\left(s_{(t)}+o_{(t)}\right) \cdot \vartheta\left(\rho_{(c / d)}\right)^{B} \cdot \theta^{\text {deg }} \\
& C_{t}^{E V(\text { deg })} \\
& \quad=\sum_{h=1}^{H}\left(\left(u_{(t, h)}\right.\right. \\
& \left.\left.\quad+v_{(t, h)}\right) \cdot \alpha_{t, h} \cdot \vartheta\left(\rho_{(c / d)}\right)^{E V} \cdot \theta^{\text {deg }}\right)
\end{aligned}
$$

Equations $(22,23)$ represent the cost of battery capacity degradation for stationary battery and EV batteries respectively. Here, we have assumed the cost of battery degradation ' $\theta$ deg' to be $0.23 \$ / \mathrm{Wh}[16]$ for simulations.

\section{Datasets}

The proposed strategy is validated using real data. The details of the datasets are presented in the following subsections.

1) Apartment building load and tariff: Modelling was based upon actual electricity meter data and the time of use (TOU) tariff (Fig. 2) structure for a residential apartment building in Australia [17]. The building consists of five floors with four individual apartments on each floor and a ground floor with parking space. It is assumed that each apartment has its own designated parking space and a Level-1, bidirectional EV charger at $220 \mathrm{~V}, 15 \mathrm{~A}, 3 \mathrm{~kW}$ charging/discharging power with $10 \%$ losses, as used by [15], [18]. Each apartment has a floor surface of $92 \mathrm{~m} 2$. Therefore, the roof has a total area of $369 \mathrm{~m} 2$. Due to shading effects (e.g., tilted solar PV panels and other obstacles), the roof can only be partially covered with a perfectly oriented solar PV installation. This available surface has been set to $65 \%$ of the roof surface, i.e., $240 \mathrm{~m} 2$ [7]. 


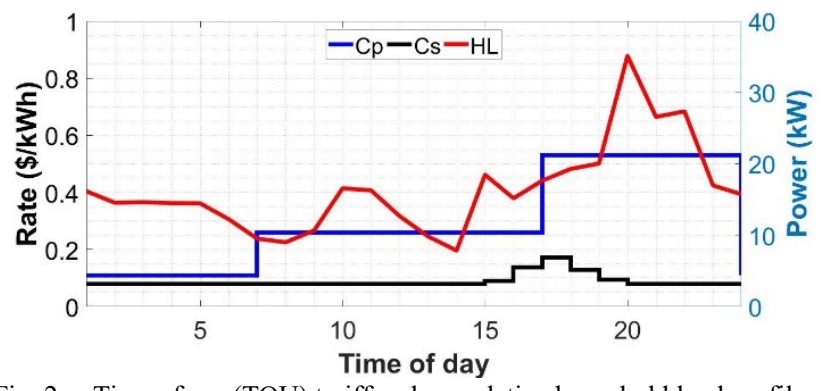

Fig. 2. Time of use (TOU) tariff and cumulative household load profile

2) Solar PV System: The solar PV power production profile is synthetically generated using the tool described in [19]. Based on the manufacturer's data and the available roof area, the solar PV system for the apartment block has a peak power of about $45.78 \mathrm{kWp}$. The efficiency of DC-AC inverter is assumed to be $95 \%$ efficient. It is assumed that the panels are perfectly oriented to generate maximum annual electricity for the considered location as specified in [6]. For simulations we have used the specifications mentioned in Table I.

TABLE I. SPECIFICATIONS FOR SOLAR PV PANELS

\begin{tabular}{lc}
\hline Parameters & Specifications \\
\hline Nominal Power (PNOM) & $327 \mathrm{~W}$ \\
Rated Voltage (VMPP) & $54.7 \mathrm{~V}$ \\
Rated Current (IMPP) & $5.98 \mathrm{~A}$ \\
Open-Circuit Voltage (VOC) & $64.9 \mathrm{~V}$ \\
Short-Circuit Current (ISC) & $6.46 \mathrm{~A}$ \\
Power Temp Coef. & $-0.38 \% /{ }^{\circ} \mathrm{C}$ \\
Voltage Temp Coef. & $-176.6 \mathrm{mV} /{ }^{\circ} \mathrm{C}$ \\
Current Temp Coef. & $3.5 \mathrm{~mA} /{ }^{\circ} \mathrm{C}$ \\
\hline
\end{tabular}

3) Electric vehicles \& travel data: Our simulations assumed that each household had one EV with a rated battery capacity of $24 \mathrm{kWh}$ and a useful battery capacity of $19.2 \mathrm{kWh}$ (i.e. $80 \%$ depth of discharge) as used by [15], [18]. Data for vehicle travel/usage pattern was extracted from The Victorian Integrated Survey of Travel and Activity (VISTA) [20]. Vehicles arrival/departure times and travel distances for all trips were extracted from VISTA data and the EV availability matrix for 20 households was developed Fig. 2.

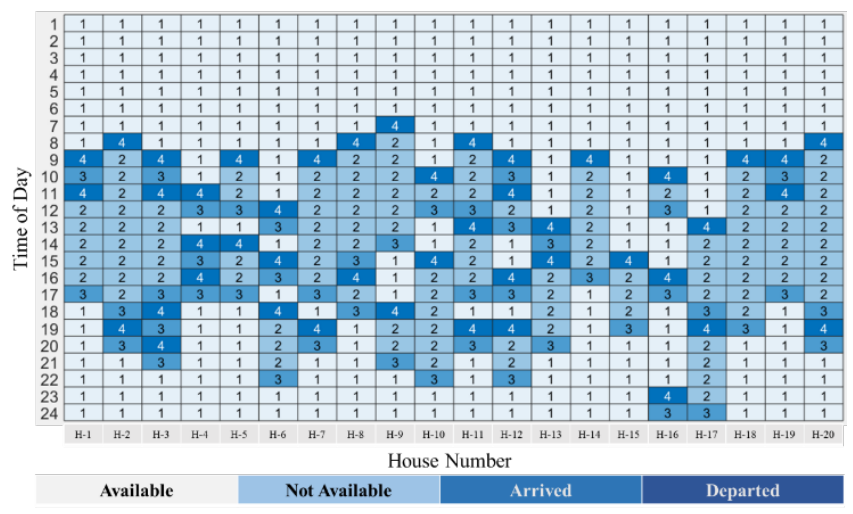

Fig. 3. EV availability matrix

4) Battery Storage: We assumed $20 \mathrm{BS}$ modules, each with $14 \mathrm{kWh}$ capacity and $5 \mathrm{~kW}$ charging/discharging power at $50 \mathrm{~Hz}, 230 \mathrm{VAC}$ and $50 \mathrm{VDC}$ (internal battery voltage).

\section{ANALYSIS \& RESULTS}

Fig. 4. shows the power flow from different energy resources in the system for ABS. The net power drawn from the grid is considerably reduced in the ABS (i.e. Pg-ABS), compared to the BC (i.e. Pg-BC). The proposed ABS not only reduces the cost of energy consumption for the system but also reduces the load on grid. The ABS also utilizes the available solar PV and BS energy systems to minimize the overall cost for the aggregator.

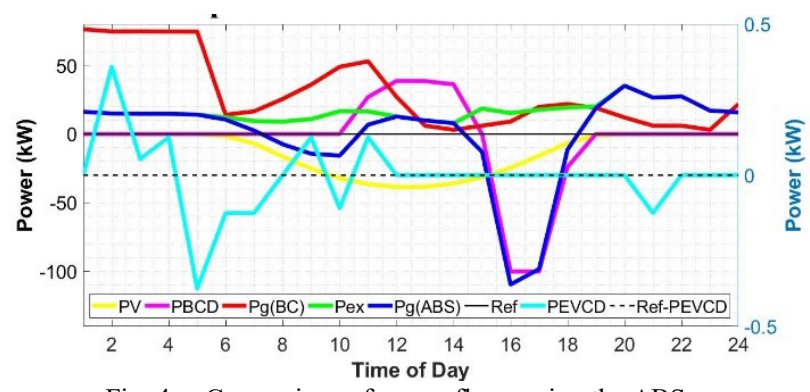

Fig. 4. Comparison of power flows using the ABS

The results of ABS are summarized in Table II. It is clear from the cost figures that $\mathrm{ABS}$ significantly reduces the cost of energy consumption for the aggregator compared to the unoptimized base-case (BC). The cost of energy consumption for individual household is also reduced as a result of overall system cost optimization.

TABLE II. ABS COMPARISON WITH BASE-CASE

\begin{tabular}{cccc}
\hline \hline Parameters & ABS & BC & Diff \\
\hline Aggregator & $-\$ 51.25$ & $\$ 151.27$ & $-\$ 202.52$ \\
Household & $\$ 130.34$ & $\$ 200.47$ & $-\$ 70.14$ \\
PV & $-\$ 28.30$ & $-\$ 9.86$ & $-\$ 18.44$ \\
BS & $-\$ 22.96$ & $\$ 27.77$ & $-\$ 50.73$ \\
EV & $\$ 0.09$ & $\$ 70.08$ & $-\$ 69.99$ \\
\hline \hline
\end{tabular}

A simple cost/benefit analysis was performed and the results are tabulated in Table III. The payback period for the initial investment on solar PV and BS is approximately 3years.

TABLE III. COST-BENEFIT ANALYSIS FOR ABS

\begin{tabular}{lc}
\hline \hline PARAMETERS & ABS \\
\hline Cost of unit PV panel [21] & $\$ 525$ \\
No. of PV panels installed & 140 \\
Total cost of PV panels & $\$ 73,500$ \\
Cost of unit BS [22] & $\$ 8000$ \\
No. of BS units installed & 20 \\
Total cost of BS units & $\$ 160,000$ \\
Estimated Daily Savings & $-\$ 203$ \\
Estimated Yearly Savings & $-\$ 73,922$ \\
Approx. Payback Period (Years) & 3.2 \\
\hline \hline
\end{tabular}

\section{APPLICATIONS}

This paper presents the numerical validation of the proposed aggregator based strategy (ABS) to minimize the cost of energy consumption by optimal utilization of the available energy resources for an apartment building. However, this strategy is equally applicable to an aggregator of microgrids with a mix of residential and commercial buildings to achieve the following objectives;

1. minimizing cost of energy consumption

2. minimizing the energy drawn from the grid 


\section{CONCLUSION}

In this work we have developed a model and strategy to determine the optimal utilization of energy resources available in a high density apartment, including the use of electric vehicles for energy management and transport. The proposed methodology utilizes all possible available energy producers, consumers and prosumers, combined in a single system to minimize the cost of energy consumption, taking into account time of use tariffs for individual households in a high-density apartment building, whilst also considering typical electric vehicle transport needs, and battery capacity degradation and associated costs.

The results show that the proposed ABS is not only capable of reducing the cost of energy consumption for the aggregator but also significantly reduces the energy drawn from the grid by optimal utilization of the available energy resources. The cost-benefit analysis show that the pay-back period for capital investment in solar PV panels and battery storage is approximately 3 years, which is much less than the lifetime of the assets (battery storage and solar PV panels).

The scalability of the proposed strategy makes it adaptable for a larger network with higher penetration level of EVs. The proposed strategy will be evaluated with diverse EV usage data and larger network in the future researches by the authors. Future researches will also focus on the detailed cost-benefitanalysis and pay-back period considering all costs involved, which was not considered in this paper.

\section{ACKNOWLEDGMENT}

S.R., U.I, and M.S.H. are supported by Macquarie University Research Scholarships.

\section{REFERENCES}

[1] IEA (International Energy Agency), "Energy Technology Perspectives $2017, " 2017$.

[2] ERTRAC, "European Roadmap Electrification of Road Transport," 2012.

[3] W. Kempton and S. E. Letendre, "Electric vehicles as a new power source for electric utilities," Transp. Res. Part D Transp. Environ., vol. 2, no. 3, pp. 157-175, 1997.

[4] G. S. Georgiou and P. Christodoulides, "A Linear Programming Approach to the Optimal Utilization of Renewable Energy Sources in Buildings," in 2017 52nd International Universities Power Engineering Conference (UPEC), 2017, pp. 1-6.

[5] R. K. Bonthu, H. Pham, R. P. Aguilera, and Q. P. Ha, "Minimization of Building Energy Cost by Optimally Managing PV and Battery Energy Storage Systems," in 2017 20th International Conference on Electrical Machines and Systems (ICEMS), 2017, pp. 1-6.

[6] K. Æ. Vedat, "A Modelling Study of Renewable and Stored Energy Sharing and Pricing Management System Developed for MultiApartment Complexes," in IEEE PES Innovative Smart Grid Technologies, Europe, 2014, pp. 1-6.

[7] J. Van Roy, N. Leemput, F. Geth, R. Salenbien, J. Büscher, and J. Driesen, "Apartment Building Electricity System Impact of Operational Electric Vehicle Charging Strategies," IEEE Trans. Sustain. Energy, vol. 5, no. 1, pp. 264-272, 2014.

[8] C. Cao, M. Cheng, and B. Chen, "Optimal Scheduling of PEV Charging / Discharging in Microgrids with Combined Objectives," Smart Grid Renew. Energy, vol. 7, no. 4, pp. 115-130, 2016.

[9] A. K. Awashima, T. Y. Amaguchi, R. S. Asaki, S. I. Nagaki, T. S Uzuki, and A. I. To, "Apartment Building Energy Management System in Group Optimization with Electricity Interchange Using In-Vehicle Batteries," SICE J. Control. Meas. Syst. Integr., vol. 8, no. 1, pp. 5260, 2015

[10] A. Kawashima, "Energy Management Systems Based on Real Data and Devices for Apartment Buildings," in IECON 2015 - 41st Annual
Conference of the IEEE Industrial Electronics Society, 2015, pp. 32123217.

[11] T. Yamaguchi et al., "Model Predictive Control of Car Storage Battery in HEMS Considered Car Traveling," in The SICE Annual Conference 2013, Nagoya, Japan, 2013, pp. 1352-1358.

[12] S. Yoon, Kanggu Park, and E. Hwang, "Connected electric vehicles for flexible vehicle-to-grid (V2G) services," in 2017 International Conference on Information Networking (ICOIN), 2017, pp. 411-413.

[13] J. Torres-Moreno et al., "Energy Management Strategy for MicroGrids with PV-Battery Systems and Electric Vehicles," Energies, vol. 11, no. 3, p. 522, Feb. 2018.

[14] M. R. K1lınc and N. V. Sahinidis, "Exploiting integrality in the global optimization of mixed-integer nonlinear programming problems with BARON," Optim. Methods Softw., vol. 33, no. 3, pp. 540-562, May 2018.

[15] S. Rafique and G. E. Town, "Potential for electric vehicle adoption in Australia,” Int. J. Sustain. Transp., pp. 1-10, Sep. 2018.

[16] My Nissan Leaf, "Update on Nissan LEAF Battery Replacement," 2014. [Online]. Available: http://www.mynissanleaf.com/viewtopic.php?f=4\&t=17168. [Accessed: 01-Oct-2018].

[17] M. S. H. Nizami, M. J. Hossain, K. Mahmud, and J. Ravishankar, "Energy Cost Optimization and der Scheduling for Unified Energy Management System of Residential Neighborhood," Proc. - 2018 IEEE Int. Conf. Environ. Electr. Eng. 2018 IEEE Ind. Commer. Power Syst. Eur. EEEIC/I CPS Eur. 2018, no. Lv, pp. 1-6, 2018.

[18] S. Rafique and G. Town, "Aggregated impacts of electric vehicles on electricity distribution in New South Wales, Australia," Aust. J. Electr. Electron. Eng., vol. 14, no. 3-4, pp. 71-87, Oct. 2017.

[19] S. Pfenninger and I. Staffell, "Long-term patterns of European PV output using 30 years of validated hourly reanalysis and satellite data," Energy, vol. 114, pp. 1251-1265, 2016.

[20] "Victorian Integrated Survey of Travel and Activity (VISTA)," Department of Transport, 2018. [Online]. Available: https://transport.vic.gov.au/about/data-and-research/vista/vista-dataand-publications. [Accessed: 01-Oct-2018].

[21] "327W SunPower E20 Solar Panel." [Online]. Available: https://www.solaronline.com.au/327w-sunpower-e20-solarpanel.html. [Accessed: 25-Feb-2019].

[22] "Tesla Powerwall 2 Specs \& Price." [Online]. Available: https://www.canstarblue.com.au/electricity/brands/tesla-powerwall/. [Accessed: 25-Feb-2019]. 